\title{
Erratum to: Three-year clinical evaluation of a two-step self-etch adhesive with or without selective enamel etching in non-carious cervical sclerotic lesions
}

\author{
Esra Can Say • Emre Özel • Haktan Yurdagüven • \\ Mübin Soyman
}

Published online: 4 February 2014

(C) Springer-Verlag Berlin Heidelberg 2014

Erratum to: Clin Oral Invest

\section{DOI 10.1007/s00784-013-1123-z}

The original version of this article inadvertently contained a mistake. There has been some mistakes in Table 6 but already corrected here.

Table 6 Results at baseline and 1, 2 and 3 years (n;\%)

\begin{tabular}{|c|c|c|c|c|c|c|c|c|c|}
\hline \multirow[b]{2}{*}{ Category } & & \multicolumn{4}{|c|}{ AdheSE non-etch } & \multicolumn{4}{|c|}{ AdheSE etch } \\
\hline & & $\begin{array}{l}\text { Baseline } \\
(\mathrm{n}=52)\end{array}$ & $\begin{array}{l}1 \text { year } \\
(\mathrm{n}=52)\end{array}$ & $\begin{array}{l}2 \text { years } \\
(\mathrm{n}=50)\end{array}$ & $\begin{array}{l}3 \text { years } \\
(\mathrm{n}=46)\end{array}$ & $\begin{array}{l}\text { Baseline } \\
(\mathrm{n}=52)\end{array}$ & $\begin{array}{l}1 \text { year } \\
(\mathrm{n}=52)\end{array}$ & $\begin{array}{l}2 \text { years } \\
(\mathrm{n}=50)\end{array}$ & $\begin{array}{l}3 \text { years } \\
(n=46)\end{array}$ \\
\hline Retention & & $52(100)$ & $52(100)$ & $49(98)$ & $42(91.5)$ & $52(100)$ & $52(100)$ & $50(100)$ & 45 (97.9) \\
\hline \multirow[t]{3}{*}{ Marginal Discolouration } & A & $52(100)$ & $49(94.2)$ & $35(71.4)$ & $17(40.48)$ & $52(100)$ & $52(100)$ & $45(90)$ & $39(86.67)$ \\
\hline & $\mathrm{B}$ & 0 & $3(5.8)$ & $14(28.6)$ & $25(59.52)$ & 0 & 0 & $5(10)$ & $6(13.33)$ \\
\hline & $\mathrm{C}$ & 0 & 0 & 0 & 0 & 0 & 0 & 0 & 0 \\
\hline \multirow[t]{3}{*}{ Marginal adaption (enamel side) } & A & $52(100)$ & $49(94.2)$ & $36(73.47)$ & $24(57.14)$ & $52(100)$ & $49(96.16)$ & $44(88)$ & $39(86.67)$ \\
\hline & $\mathrm{B}$ & 0 & $3(5.8)$ & $13(26.53)$ & $18(52.86)$ & 0 & $3(3.84)$ & $6(12)$ & $6(13.33)$ \\
\hline & $\mathrm{C}$ & 0 & 0 & 0 & 0 & 0 & 0 & 0 & 0 \\
\hline \multirow[t]{3}{*}{ Marginal adaptation (dentin side) } & A & $52(100)$ & $51(98.1)$ & $44(89.8)$ & $36(85.71)$ & $52(100)$ & $49(96.16)$ & $47(94)$ & $40(88.89)$ \\
\hline & $\mathrm{B}$ & 0 & $1(1.9)$ & $5(10.2)$ & $6(14.29)$ & 0 & $3(3.84)$ & $3(6)$ & $5(11.11)$ \\
\hline & $\mathrm{C}$ & 0 & 0 & 0 & 0 & 0 & 0 & 0 & 0 \\
\hline
\end{tabular}

The online version of the original article can be found at http://dx.doi.org/ 10.1007/s00784-013-1123-z.

E. C. Say $(\bowtie) \cdot H$. Yurdagüven $\cdot$ M. Soyman

Department of Operative Dentistry, Faculty of Dentistry, Yeditepe

University, İstanbul, Turkey

e-mail: esracansay@yahoo.com

E. Özel

Department of Restorative Dentistry, Faculty of Dentistry, Kocaeli

University, Kocaeli, Turkey 